\title{
Ambiguity of Time, Self, and Philosophical Explanation in Merleau-Ponty, Husserl, and Hume
}

\author{
LAURA DUHAN \\ Claremont Graduate School
}

In the Phenomenology of Perception, Maurice Merleau-Ponty criticizes the "piejudice toward the objective world"l which, he says, contaminates philosophy. Under the influence of this prejudice, philosophers have used "objective data"--data which does not come from perception but from other sources such as science--to study perception, instead of using the acbeen subjective data of perception. The result has knowledge of inaccurate theories of perception and of this. One expression of Merleall-Ponty's critique time prejudice is his thesis of the ambiguity of time, which he approaches through a discussion of the constitution of the body as an object. Although ination-Ponty does not explicitly say so, a close exampraches to philosophy reveals that object-oriented apbiquity of the am-

The four sections of this paper lead from a description of Merleau-Ponty's ideas about time and the self to their implications for the general structure of philosophical explanation. Part I describes MerleauPonty's discussion of the objective and subjective faces of experience of the body, understood through the ambiguity of time. Two major themes or theses are identified: (1) an understanding of the constitution of the body as object will contribute to an understanding of the constitution of the world as object, and (2) the ambiguity of time characterizes all being-in-theworld. Part I investigates the roots of MerleauPonty's two major theses in the work of Husserl, and notes where Merleau-Ponty agrees or disagrees. Part II provides an example of the interweaving of the two theses by interpreting the work of David Hume along Merleau-Ponty's lines. Part IV provides a critique of the types of explanations offered by Hume and Husserl. as based on an inadequate understanding of the ambiguity of time.

Three limitations of the paper must be noted. First, the ideas are not yet informed by their integration into the lived experience of the author. Second, 
the discussion of time in this paper focuses on the relationship of past and present. It does not take adequate concern with the role of the future in the ambiguity of time, and, therefore, with the role of the future aspect in the constitution of the self or in philosophical explanation. The justification for it is Merleau-Ponty's emphasis on the interaction of past and present. Third, although the paper discusses MerleauPonty's criticism of object-oriented explanation in philosophy, it does not adequately articulate the new form of explanation which emerges from that criticism.

In Phenomenology of Perception Merleau-Ponty rejects the doctrines of physiological psychology which describe perception in terms of the organs of sensation by defining "the visible |as| what is seized upon with the eyes; the sensible |as| what is seized upon by the senses." 2 Scientists who believe this usually establish a point by point correspondence and constant connection between the stimulus and elementary perception. If perception -were correctly defined as what one perceives through the senses, people with injured sensory systems would not perceive objects as healthy people do. Yet medical research shows that injured sensory systems do keep sensation constant, in accordance with a basic pattern of perceptual experience. For MerleauPonty, this pattern points to what emerges as objective rather than subjective in human experience. He investigates the basic pattern through which people perceive their bodies, since the body is the vehicle with which we navigate the world. If we understand the constitution of the body as object, we will understand some aspects of the constitution of the world as object.

Merleau-Ponty chooses to discuss and redefine the problem posed by the phenomena of phantom limb (the illusion that an amputated limb still exists) and anognosia (refusal by a paralyzed patient to acknowledge the paralysis). If a person conceives of the world in terms of the possible interactions his/her body can have with it, or as a series of actions s/he can perform upon it, the person with phantom limb or anognosia experiences the world through his/her former body. The paralyzed person still perceives and attempts to use the floor as something $s /$ he can walk on; the amputee feels the cold night air as something that causes muscular cramps. Objects which were formerly one side of an interaction take on a character of their own. The subjectively experienced becomes an object, standing alone, independently of a person's perception or interaction with it. In the cases of phantom limb and anognosia, this is made possible-by a body that gets stuck at a certain stage of experience, at a certain point in 
time. The body is no longer the body of a particular person, no longer a personal body. It has become impersonal, an objective, generalized body.

Merleau-Ponty seems to suggest that all of us, healthy or unhealthy, from time to time experience an impersonal body as well as our personal body, and that this objective, physiological body appears as a necessary condition for us to have any personal experience. We believe that if we had no objective body, no sensory organs, no central nervous system, we woud experience nothing at all. Yet we learn about our sensory organs by perceiving with them; we learn about our central nervous system through a science which is presumably based on observable data. Merleau-Ponty states the problem succintiy:

This paradox is that of all being in the world: when I move towards a world I bury my perceptual and practical intentions in objects which ultimately appear prior to and external to those intentions, and which nevertheless exist for me only in so far as they arouse in me thoughts or

Rather than try to show that the paradox is only a confusion and not a paradox, Merleau-Ponty accepts it as a tension between irreducibles and sets out to explain why they are irreducible to one another.

Most of the time personal existence represses the organism without being able either to go beyond it or to renounce itself; without, in other words, being able either to reduce the organism to its existential self, or itself to the organ-

Merleau-Ponty describes the relationship between the personal body and the impersonal body as one of "repression," a term he borrows from psychoanalysis. Taber's Cyclopedic Medical Dictionary defines repression as a "refusal to entertain distressing or painful ideas. . " complex, "a subconscious idea (or group of ideas) which has become associated with a repressed wish or emotional experience and which may influence behavior although the person may not have any appreciation of the conncection between the repressed thoughts or |sic| actions." The Dictionary suggests that a complex may become the very framework through which a person perceives the world. For example, a child who has grown up with an authoritative father may continue throughout her life to rebel against the suggestions of any older person in a position of authority. Emotional trauma has rendered an experience--in this case submission to authority--so painful that normal or healthy develop- 
ment in that area could not proceed. The woman's interaction with authority figures is stuck at a particular stage in time. Despite each teacher or employer's individual character, what the woman puts into and receives from each relationship remains the same. Although the relationship is an interaction, her experience does not acknowledge that.

A complex "may, [however] be harmless... . i.e. an artist sees every object with a view to a possible picture and is said to have established a complex for art." Most of the time the customary/impersonal body functions as such a harmless complex. It provides a background or a structure which gives shape to our (personal) bodily experiences, makes them take a certain form, helps us interpret them in a uniform way. The personal body provides the content for our experience; the customary body provides its boundaries. In the case of extreme trauma, such as paralysis or loss of limb, the real content of personal bodily experience is too painful to acknowledge and bodily experience gets stuck at an earlier stage. The repressed impersonal body (in the form of past experience) takes over and provides the content of present experience. The relationship of repression is not an accidental metaphor but an inescapable shape taken by our experience of ourselves in time.

The fusion of soul and body in the act, the sublimation of biological into personal existence, and of the natural into the cultural world is made both possible and precarious by the temporal structure of our experience.

In Merleau-Ponty's vision, the present has an immediacy which the past lacks. The present is indubitable, alive, happening before our very eyes. The past draws its life from the present in a twofold way. The present includes a past which is supposed to have happened before it. We have access to that past, and, in so far as it is related to present events and experiences, we can reinterpret and reconstruct it. On the other hand, the past was once a present, and so it still carries that indubitable immediacy--it happened as it happened and that's that. The past draws its authority from the fact that it, was once a present, and its flexibility from the fact that it can be reinterpreted in the light of present events. Without the present, the past is nothing. And yet there is no present without a past presupposed, at least in the realm of ordinary human experience. Merleau-Ponty describes the impersonal/objective life as analogous to the past and the personal/cultural life as analogous to the present. Impersonal/objective life draws both its authority and its flexibility from personal/subjective life. Objective knowledge about the body and the world 

derives its authority from its roots in personal
experience. Its flexibility lies in the fact that as personal experience changes, it can also change. At the same time, the objective world provides a structure, a framework, a necessary condition for personal experience, just as the past provides a history on which to hang the present.

Merleau-Ponty seems to be arguing as follows: If we understand the constitution of the body as object, we can understand the genesis of the world as object. Objective and subjective are two irreducible faces of our experience of our body. Their relationship is one of repression. Repression is made possible by the ambiguity of time. Because of the ambiguity of time, objective and subjective are two irreducible faces of our experience of the world. Two steps in the argument require further elucidation: (1) how we move from an understanding of our body as object to an understanding of other things in the world as objects; and (2) why the ambiguity of time can function as a central metaphor to explain being-in-the-world. The roots of these assumptions can be found in the writings of Edmund Husser1, the phenomenologist upon whose work Merleau-Ponty builds, accepting some ideas and reject-
ing others.

In Ideas Husserl outlines a program for phenomenological investigation of philosophical questions. He introduces the main tool of phenomenology, the phenomenological reduction, and sketches out preliminary findings on a variety of topics, including the nature of the self or ego. An investigator performs the phenomenological reduction by "putting into brackets," or setting aside, the natural attitude in which we experience ourselves living in a real, concrete, existent world. The investigator focuses only on the data of consciousness, putting aside all questions about the objective world. The reduction enables the investigator to discern exactly what in experience is given essentially by consciousness. According to the theory of intentionality which underlies the reduction, consciousness constitutes and picks out its objects from its stream of pure experience. Consciousness is able to do this without reference to existence or the external world. A thing existing in the external world is only recognized as the fulfillment or verification of a completely constituted meaning/object or, as Husserl often calls it. "intentional unity."

Merleau-Ponty does not accept the consequence of this theory, the closed consciousness. For MerleauPonty, the subjective and the objective interact to constitute our experience of the world. Experience involves a reference to things existing in the world. 
Therefore, he does not use Husserl's method of reduction, but adopts a milder method of bracketing objective knowledge, which allows him to apprehend and use the data of perception in its original form.

Using the phenomenological reduction, Husserl discovers two faces of the self.

We have, then, to take our own case, on the one side the psychological point of view in which the glance is directed upon experience as the natural standpoint dictates, upon an experience of joy, for instance, as an inner state of feeling of a man or an animal. On the other side we have woven together with this, as an essential possibility, the phenomenological point of view, according to which, all transcendences having been disconnected, the glance is directed in reflection upon the absolute pure consciousness, giving us the apperception of an absolute experience in its intimate subjective flow...

The empirical ego represents our experience of the self in the natural attitude and the phenomenological ego represents the self in closed consciousness which we find after performing the reduction. The empirical ego is the fulfillment or manifestation of the phenomenological ego in the world. Consciousness manifests in the world in the form of a "state of consciousness." The essence or distinguishing characteristic of a state of consciousness is that it appears as a property of a body. A state of consciousness is what some body, human or animal, is thinking, feeling or experiencing at a particular point in time. Consciousness is able to participate in the external world by being linked to a body. However, this linkage is somehow accomplished within closed consciousness, for a state of consciousness is an intentional unity constituted within the stream of pure experience. Merleau-Ponty seems to accept Husserl's idea that the body is the point at which consciousness enters the world. The empirical ego is the first or primary object in our experience by virtue of being our point of entry into the objective world. If we understand how the body manages the objective/subjective paradox, we can understand how the paradox functions in our experience of the world.

Merleau-Ponty's ideas about the ambiguity of time are also derived from Husserl. Husserl accepts from Kant the idea that time is the form of, and a condition of, inner experience. But for Husserl, time is not simply a succession of representations. In "The Lectures on Internal Time Consciousness from the Year 1905," he explains his view that a series of discrete present moments (which become a series of discrete past moments) is not sufficient to constitute experience as we know it. A complex object, such as a melody, could 
hot be an object of experience if it were simply a succession of notes. Our experience of the note we're hearing now as part of a melody is only possible if we somehow retain the other notes we've heard and hear them all as part of a single tune. This holding in consciousness of past perceptions which co-constitute the present is called "retention." In turn, memory of the past is co-constituted by present perception in two ways: (1) memory, as distinguished from fantasy, includes an image of something which was perceived, i.e., something which was present to us; (2) remembering something is an act in which we are presently engaged, when we are engaged in it. Although these ideas about the interweaving of the faces of time form the basis for Merleau-Ponty's thesis of the ambiguity of time, for Husserl, time is not ambiguous. He believes that the difference between past and present experience is clear and distinct. The only difference between an object in closed consciousness appearing as past and appearing as future is its mode of appearing--a desk appearing as a perception and a desk appearing as a memory.10 Merleau-Ponty would disagree, and would suggest that Husserl cannot describe experience correctly if he accepts the primacy of the object as a basic form. Merleau-Ponty would suggest that an object actually goes through changes in its constitution, since one of the features of past experience is that it can be reinterpreted and reconstituted. Husserl does not take into account pathological cases such as phantom limb and anognosia in which past experience appears as present, yet appears neither in the form of memory nor of anticipated perception.

\section{1 I}

David Hume is an empiricist philosopher whose overall project in A Treatise of Human Nature Merleau-Ponty would reject as obviously based on a prejudice towards the objective world. Hume's overall project is to describe the way the atoms of experience combine to constitute human knowledge, emotions and society. These atoms are called impressions ("all our sensations, passions and emotions, as they make their first appearance in the soul") and ideas ("the faint images of these in thinking and reasoning")." "What these atoms specifically are is determined by the objects of sensation. A complex impression of a red cube is analyzed as a set of simple impressions of red, solidity and cubicity, for example. Hume then attempts to reconstruct perception as it is actually experienced from these simple impressions. Hume recognizes that he has difficulty choosing between two accounts of many of the subjects he treats. One account is that of the vulgar, who take at face value the fictions which are suggested by sense-experience. The other is the philo- 
sophical account based on the theory of impressions and ideas. Hume's distinction between these two types of accounts is reminiscent of/anticipatory of MerleauPonty's distinction between the subjective experience of perception vs. objective data which relies more on scientific theory than it does on perception. In some of the topics he treats, Hume proposes a third explanation which mediates between the two accounts. In the case of the self, Hume simply makes use of both accounts. His relative ranking of the two reveals deeper dimensions of his object-orientation.

The carefully argued account of the concept of self or personal identity which Hume presents in Book $I$ of $A$ Treatise of Human Nature appears to be contradicted by his introduction of a radically different experience of the self in Book II. In Book I Hume claims that, "when $I$ enter most intimately into what I call myself, I always stumble upon some particular perception or other . " "12 Hume claims that he has no distinct impression of anything he can call himself apart from any particular perception, referring to the self as a "bundle of perceptions."13 He explains how those perceptions are organized so as to give an illusion or false idea of the self. What we call the "self" is in reality a system of distinct perceptions linked by cause and effect and memory. One thought or perception gives rise to another. Through memory we become aware of this chain of perceptions; through memory, new perceptions come to resemble past ones. In Book II. Hume speaks as if we do have an impression of the self. This idea or impression of self is "always intimately present to us" and is the liveliest impression imaginable." (In the Treatise, the livelier the impression the more credible it is.) Hume uses this description of the self as the basis for his complex explanation of sympathy, which is the basis for all human relationships.

Hume needs both of his intuitions about the self to make his philosophical account of human nature--from the intellect to the passions--consistent. That ambiguity about the nature of the self should be essential to a consistent philosophical picture demands our attention, demands an account. Merleau-Ponty's description of the ambiguity of time suggests such an account, as follows: One self is historical, described by the chain of mental events of a person's life. The other self is an ahistorical, present experience of self. The two remain distinct, on Hume's model, because every atom of experience is discrete. He cannot and would not say that every present includes within itself a past or a future. He views time as an illusion created by the succession of impressions and ideas. Therefore, having a past and future is a characteristic of the self as a bundle of discrete perceptions. Having a present is a characteristic of a single discrete ex- 
perience of the self. Both kinds of experience are necessary to give us a coherent experience of the self
in time.

Our experience of the self takes its place in a line of perceptions, none of which, says Hume, is a perception of the self. In becoming part of the historical self, the present experience of self loses its personal character, its presence, its fullness of experience. The self which Hume describes in Book II merits no word reconciling or acknowledging his deviation from his doctrine in Book I. For some reason Hume considers the historical, total self more important than the full experience of the self he describes in Book II. Merleau-Ponty has explained that our present experience only makes sense if we apprehend it within the framework of our "past" or repressed existence. In Hume's scheme, the historical self described in Book I is the framework of personal experience--a succession of perceptions connected by causation and resemblance. both with the aid of memory. One or a few impressions of the self will not change this basic structure of personal experience; these impressions simply take their place in the scheme of experience. The isolated experiences of the self described in Book II are not enough to suggest an alternate structure for personal experience, and hence do not pose any serious challenge to Hume's account in Book I.

Personal history is the essence of Hume's description of the self. The self is not a substance, but a history, a framework of which all present and future experience becomes a part. The essence of this history, the principle which unifies it, is causation. The relation of ideas called causation allows us to infer that one experience or perception will follow another, because observation of past regularities suggests it. In Hume's system, causation is at the root of all our scientific and commonsense reasonings about the world. Although all our perceptions are distinct, we are able to observe empirical regularities which lead us to infer that $B$ always follows upon $A$, or that "A causes B." Hume borrows the idea that perceptions cause each other from his account of how we reason about the world and applies it to his account of the self. Since our propensity to infer that perceptions cause each other enables us to construct a coherent experience of the world across time, causation must be the essential link between perceptions which entitles us to a single, coherent experience of a personal history.

Both Husserl and Merleau-Ponty would reject this reasoning, for it begins with the world of objects and constructs a subjective or personal experience on the terms of the objective world. Husserl would describe a closed, self-sufficient self without reference to the world of objects. Merleau-Ponty would insist that 
knowledge about the objective world is not the proper starting point from which to describe our experience of the self. For Merleau-Ponty, the interaction of self or body with the world make both what they are. The world is apprehended through and as the activities we can perform upon it; at the same time the objects that are in the world inform us what actions we can perform. If we begin with the objective world, we will only construct an epiphenomenal mirror of it, just as Hume's account of personal history does.

\section{IV}

Hume's account and even Husserl's account seem to be satisfying in a way that Merleau-Ponty's is not. Hume and Husserl, at least, tell us something about the foundations of some aspect of experience. Hume tells us that the structure of personal experience mirrors the structure of the world of objects. Husserl tells us that structures or essences generated within closed consciousness are mapped onto the world. Merleau-Ponty will not tell us whether the subjective or the objective face of experience provides the meaning for our experience of the self. Moreleau-Ponty tells us neither (a) the principle through which subjective experience becomes objective nor (b) the way experience of the self forms the basis for experience of the world. Instead, he offers (a) the fact that subjective and objective are irreducible faces of our experience and (b) a description of our experience of the self which we can use as an analogy to understand our experience of the world. What's more, his explanation of "the genesis of the objective world" (as he describes his endeavor $)^{15}$ is based on the objective, which he is trying to explain, as well as on the subjective.

Husserl's and Hume's explanations resemble those of theoretical physics. On such a model, an ultimate, unperceivable substratum--atomic particles--is postulated as the real cause of our experience of material things in the world. On such a model, reality has two levels: the perceived, everyday reality of tables and chairs and the conceptually distinct, more real unperceived substratum. The substratum is understood as more fundamental than the everyday reality in that we can make more accurate judgments about it. It is not contaminated or confused by the world of experience. The substratum is also understood as prior in time. As the structure that is reached through analysis (such as Husserl's phenomenological reduction or Hume's philosophical viewpoint), the substratum appears as capable of existing on its own, before it takes the particular shape or content that everyday experience supplies. It seems, for example, as if atoms existed long before they combined to form the table we perceive; as if Husserl's closed consciousness can exist without ful- 
fillment in the external world; as if we can have a structural self that is intelligible without a perception of self, on Hume's view.

But on Merleau-Ponty's view time is ambiguous : something which appears as past derives its life from the present. He would understand explanation on the model of time as ambiguous. The explanandum (the thing that is explained) is analogous to the present; the explanans (the explanation) is analogous to the past. The substratum does not have a life of its own. Its authority, flexibility and reformulatability as an explanation are derived from its relationship with its perceived manifestation. An explanation which does not change in the face of new perceptions becomes less an explanation than a paradigm, in kuhn's sense of a model structuring scientific inquiry, and in an extended sense of a principle that structures experience as a complex does.16 Such an explanation oversteps its place as analogous to a repressed past experience and begins to dominate the present, just as the impersonal body of the phantom limb patient dominates his/her bodily experience.

Thus Merleau-Ponty provides the only type of explanation he considers appropriate: one which acknowledges the interaction of present and past, perceived reality and postulated reality, subjectivity and objectivity. Although objective explanation, knowledge of a thing-in-itself, is the form of explanation used in the sciences, Merleau-Ponty criticizes its use in philosophical explanation. Experience of things as objects, of things capable of being-in-themselves, is only one face of our experience. Things-as-perceived is the other face which Merleau-Ponty stresses. Knowledge of objects presupposes a point in time at which such things are determinate, their files closed. But, says Merleau-Ponty, there is no such time, although it is assumed in scientific explanation. The past is always subject to revision in the face of present experience even as present experience depends on that past for its intelligibility. Things-inthemselves are determined to be what they are through perceptual information, even as perception depends upon the existence of things-in-themselves if it is to be intelligible.

Merleau-Ponty discovers this thesis in his investigation of the experience of the self/body. Two other descriptions of the self have been contrasted with Merleau-Ponty's. Husserl attempts to reduce the two faces of experience into one, describing things-inthemselves in terms of things-as-perceived. As a consequence, he describes a self which can exist and can apprehend itself without any contact with an external world. Hume describes things-as-perceived in terms of things-in-themselves, resulting in the description of a self which is complete without a perception of the 
self. Nevertheless, we do interact with the external world and we do have perceptions of our selves. For Merleau-Ponty, these are both facts about experience. He is not willing to label one necessary and the other accidental. Philosophers who do so label the faces of experience are acting under the influence of the prejudice of the objective world, which leads them to approach their descriptions of the self as a search for a single set of determinate characteristics. By providing the framework for a critique of Hume's and Husserl's positions on the self. Merleau-Ponty hints at and provides an example of an alternative form of explanation which recognizes the indeterminateness of objects or the ambiguity of being-in-the-world. It remains as a task for his interpreters to articulate that new form and to provide experimental examples of it in philosophy, science and social science.

\section{NOTES}

'Maurice Merleau-Ponty, Phenomenology of Perception. Trans. Colin Smith (New York: Humanities Press, 1962), 5 .

${ }^{2}$ Merleau-Ponty, 6-7.

${ }^{3}$ Merleau-Ponty, 82 .

"Merleau-Ponty, 84.

'Thomas L. Clayton, ed. Taber's Cyclopedic Medical

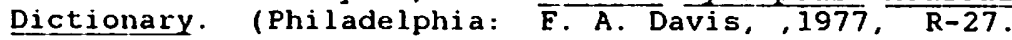

'Thomas, C-96, C-99.

'Thomas, C-99.

Merleau-Ponty, 84 .

'Edmund Husserl, Ideas: General Introduction to Pure Phenomenology. Trans. W. R. Boyce Gibson (New York: Collier, 1962), 150-1.

${ }^{10}$ Edmund Husser1, "The Lectures on Internal Time Consciousness from the Year 1905," Trans. James S. Churchill in Peter McCormick and Frederick Elliston, eds. Husserl: Shorter Works (Notre Dame: University of Notre Dame Press, 1981) 277-88.

"David Hume, A Treatise of Human Nature. (Oxford: Oxford University Press, 1983), 1 . 
${ }^{12}$ Hume, 252.

${ }^{13}$ Hume, 252.

1 "Hume, 317-18.

${ }^{15} \mathrm{Mer}$ leau-Ponty, 92 .

${ }^{16}$ Thomas Kuhn, The structure of Scientific Revolutions (Chicago: University of chicago Press, 